\title{
MANUEL COELHO MENDES DA ROCHA
}

\author{
1914-1981
}

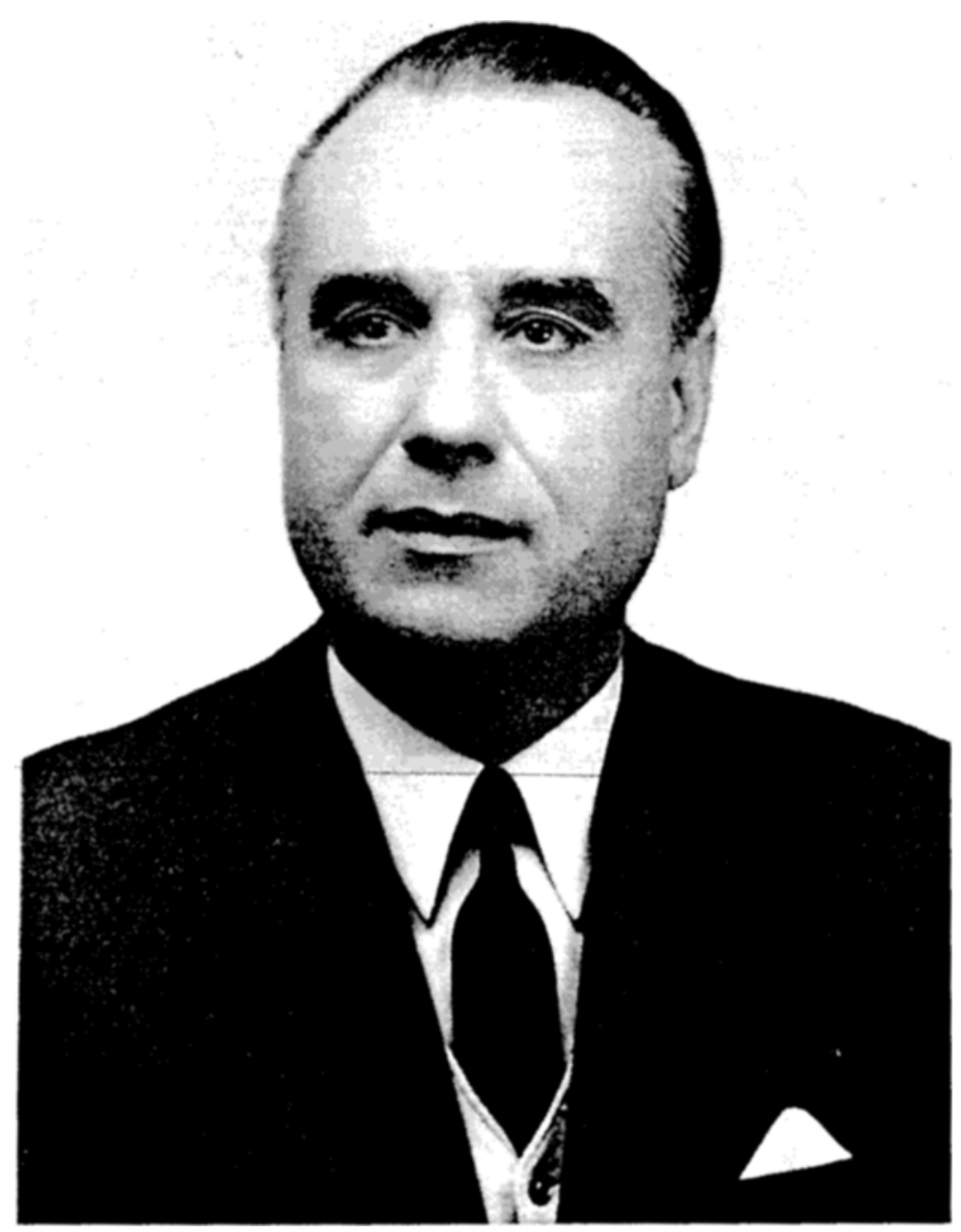

Manuel Rocha est mort le 1er août 1981. II a été l'un de ces hommes que l'on rencontre à l'origine des œuvres et des institutions. Par nature et par vocation, créateur et fondateur. Mais doué également d'une capacité d'organisation qui lui a permis de développer et de faire croître ce qu'il avait établi. Le Laboratorio Nacional de Engenharia Civil (LNEC), à Lisbonne, dont il a fait dans le monde l'un des hauts lieu des sciences et techniques de la construction, en est la preuve qu'il laisse à son pays, et de même, sur le plan international, on le trouve à l'origine de la RILEM et de la Société Internationale de Mécanique des Roches.

Ici, c'est ce dernier aspect, celui de l'homme des grandes coopérations internatiopales, qui en a fait l'un des fondateurs de la RILEM, en 1947, qu'il convient d'évoquer. En 1947. Manuel Rocha dirigeait les activités de recherche du LNEC, et il était âgé de 33 ans. Cette aptitude si tôt révélée à couvrir le champ le plus large et à en coordonner les différentes disciplines dans un programme défini par les objectifs à atteindre était l'une des caractéristiques les plus remarquables de sa personnalité et lui fit jouer un rôle majeur dans les déterminations de la RILEM

Délégué de la RILEM au Portugal, plusieurs fois membre de son Bureau, il fut aussi en 1953 l'un de ses premiers Présidents, succédant alors au Professeur Lobry de Bruyn. En fait, durant près d'un quart de siècle, sa présence et son action s'affirmèrent au sein de la RILEM avec une créative continuité. Et il est sans doute admirable que, 20 ans après avoir contribué à la naissance de la RILEM, Manuel Rocha fut l'un de ceux qui lui donnèrent ses nouvelles structures et procédures de travail actuellement en vigueur.
On sait que le colloque restreint à un nombre limité de réels spécialistes en vue de traiter un sujet strictement défini a été, est encore, l'un des modes d'activité que la RILEM a privilégiés. Or Manuel Rocha, incontestablement, a concouru plus qu'aucun autre à donner à ces colloques leurs procédures telles que nous les avons retenues et depuis codifiées. II le fit d'ailleurs par l'exemple, et les trois colloques qu'il a organisés à Lisbonne successivement sur l'observation des ouvrages (1955), l'utilisation de l'ordinateur dans le génie civil (1962) et les modèles de barrages (1963) étaient en effet exemplaires.

Ce que furent la vivacité de son intelligence toujours en éveil, son sens aigu des justes orientations, la curiosité d'un esprit ouvert à toutes les techniques avancées qui faisait de lui bien souvent un vrai précurseur, sa passion pour tout ce qui touchait à l'éducation et à l'enseignement, son brio dans la discussion que tempérait une merveilieuse courtoisie, ses collègues, qui furent aussi ses amis, s'en souviennent.

Sa disparition nous laisse mesurer ce que nous devons à Manuel Rocha et nous fait ressentir ce que nous perdons avec lui.

Maurice Fickeison

\section{QUELQUES MOTS EN HOMMAGE}

Je tiens à ajouter à la note précédente quelques mots en mémoire d'un ami très cher.

Je le connus à Lisbonne aussitôt la guerre lorsque je fis la tournée des laboratoires européens et américains. Nous y discutâmes de la possibilité de créer une union internationale des laboratoires d'essais et de recherches sur le Génie Civil après la disparition de l'Association Internationale des Essais de Matériaux. Avec l'accord de MM. Rocha, Campus et Lea et de quelques autres amis, nous fûmes amenés à créer la RILEM à Paris en 1947.

$J$ 'ai rencontré depuis Manuel Rocha à de nombreuses reprises ainsi que sa famille et ses enfants, toujours gai, toujours de caractère égal. Je ne m'attendais pas à sa disparition soudaine et $j$ 'en suis profondément peiné.

Robert L'Hermite Président Fondateur de la RILEM 